\title{
PENGARUH WAKTU PEMANASAN PADA PEMBUATAN SENYAWA ALUM DARI LIMBAH FOIL BLISTER UNTUK KEPERLUAN INDUSTRI FARMASI
}

\author{
Aji Nugroho ${ }^{1}$, Athiek Sri Redjeki $^{2}$ \\ 1,2 Jurusan Teknik Kimia, Fakultas Teknik \\ Universitas Muhammadiyah Jakarta \\ athieksri@yahoo.com
}

\begin{abstract}
ABSTRAK. Pertumbuhan ekonomi di Indonesia semakin meningkat dari tahun ke tahun, tidak terkecuali industri farmasi. Hampir semua industri farmasi dalam pengemasannya menggunakan blister yang didalamnya terdapat unsur aluminium. Padahal, jika berada bebas di lingkungan, dibutuhkan waktu 100 tahun untuk aluminium agar dapat terurai di tanah. Cara terbaik untuk mengatasi limbah aluminium tersebutadalah dengan mendaurulangnya dan mengubahnya menjadi senyawa alum AlK $\left(\mathrm{SO}_{4}\right)_{2} \cdot 12 \mathrm{H}_{2} \mathrm{O}$. Alum memiliki banyak manfaat, diantaranya sebagai penjernih air dan bahan baku obat di industri farmasi. Penelitian ini memanfaatkan kandungan aluminium dalam limbah foil blister sebagai bahan baku pembuatan senyawa alum tersebut. Foil pertama-tama dipisahkan dan dibersihkan kemudian direaksikan dengan $40 \mathrm{ml}$ kalium hidroksida pada suhu $80^{\circ} \mathrm{C}$ dengan variabel waktu pemanasan 1 jam, 2 jam, 3 jam, 4 jam, 5 jam dan 6 jam. Setelah proses pemanasan ditambahkan kedalamnya $25 \mathrm{ml} \mathrm{H}_{2} \mathrm{SO}_{4} 6 \mathrm{M}$ sambil diaduk hingga jernih dan berkurang sepertiga volumenya. Larutan kemudian didinginkan hingga terbentuk kristal alum. Kristal alum yang terbentuk dikeringkan dengan bantuan etanol dan ditimbang. Dari penelitian didapat bahwa semakin lama waktu pemanasan maka semakin tinggi rendemen yang diperoleh. Waktu optimum pemanasan adalah 3 jam dan setelah 3 jam tidak ada perubahan rendemen yang signifikan. Persamaan polinomial hubungan antara waktu pemanasan dengan rendemen alum adalah $y=-0,140 x^{2}+1,203 x+13,82$, dimana $y$ adalah rendemen alum dan $x$ adalah waktu pemanasan.
\end{abstract}

Kata kunci : limbah, farmasi, foil, alum

\section{PENDAHULUAN}

Aluminium foil merupakan salah satu limbah yang sering dijumpai di pembuangan sampah. Saat ini kemasan banyak menggunakan bungkus berlapis aluminium foil, karena bisa membuat produk tahan lama. Umumnya kemasan berlapis aluminium foil ini hanya sekali pakai saja, seperti kemasan untuk makanan, minuman, deterjen, termasuk obat-obatan.

Obat merupakan produk yang dikonsumsi oleh manusia, maka perlu ditunjang dengan kemasan yang baik dan kuat. Menurut Pilchik, 2000, jenis kemasan pembungkus obat yang umum digunakan adalah blister. Blister terdiri dari dua lapisan utama, yaitu aluminium foil dan PVC (Poly Vinyl Chloride). Oleh karena terdapat kandungan logam aluminium pada blister, maka limbahnya menjadi masalah bagi lingkungan. Limbah logam aluminium membutuhkan waktu 80-200 tahun untuk terdegradasi (Bloch, 2013) Untuk mengatasi sampah aluminium tersebut, cara terbaik yang dapat dilakukan adalah dengan mendaurulangnya menjadi senyawa alum.

Alum merupakan salah satu bahan kimia industri yang paling banyak digunakan karena kegunaan dalam industri pulp dan kertas serta untuk pengolahan air dan air limbah. Aum berfungsi sebagai koagulan, flokulan, menghilangkan kekeruhan, karena 
padatan tersuspensi dan koloid. Manfaat lain alum adalah sebagai bahan baku obat di industri farmasi, yaitu digunakan dalam pengobatan keracunan. Larutan alum 1\% hingga 4\% digunakan sebagai bahan baku pembuatan obat kumur, pengobatan radang mulut (stomatitis) dan pharingytis, dalam perkembangannya sekarang alum jarang digunakan sebagai obat kumur karena dapat merusak gigi. Alum dalam bentuk padat dan cairan digunakan sebagai hemostatik (pembeku darah), sehingga mencegah hilangnya darah berlebih pada luka, luka pada bibir juga dapat diobati dengan menyentuhkan kristal alum pada bagian yang luka. Larutan alum $0.5 \%$ digunakan dalam pengobatan keputihan. Larutan alum $2 \%$ digunakan sebagai deodorant karena sifatnya yang dapat menekan hiperhidrosis (keringat berlebih) sehingga dapat mengurangi bau badan. Larutan yang lebih pekat dapat mengeraskan lapisan epidermis pada kulit berguna untuk pengobatan luka pada kaki (Martindale, 1997).

Aluminium foil adalah bahan tipis dari logam aluminium yang digulung dengan ketebalan kurang dari $0,15 \mathrm{~mm}$ dan memiliki lebar 1,52 meter hingga 4,06 meter. Umumnya aluminium foil tidak murni berbasis logam aluminium, kombinasi aluminium dengan bahan lain seperti PVC dapat menciptakan jenis kemasan yang mampu melindungi bahan didalamnya secara maksimal. Kandungan aluminium dalam foil mencapai 99\%. Aluminium merupakan bahan yang tahan panas dan kedap terhadap udara sehingga membuat aluminum foil menjadi kemasan ideal untuk ekspor. Selain itu aluminium foil mudah dibentuk walaupun mudah berkerut. Ketahanannya terhadap panas matahari membuat aluminium foil banyak digunakan juga pada bahan-bahan kesehatan dan obatobatan (Astawan, 2008).

Alumunium foil memiliki sifat yang fleksibel, tidak tembus cahaya sehingga dapat digunakan untuk mengemas bahan-bahan yang berlemak dan bahan-bahan yang peka terhadap cahaya. Aluminum foil juga dikagumi karena karakteristiknya yang kuat, ringan dan tahan terhadap suhu tinggi. Dari segi estetika aluminium foil memiliki sifat tidak berbau, tidak ada rasa, tidak berbahaya dan higienis serta tidak mudah ditumbuhi bakteri dan jamur. Alumunium Foil menempati posisi yang penting dalam produk kemas fleksibel karena memiliki ketahanan yang memuaskan dan penampilan yang baik.Umumnya untuk kepentingan kemas fleksibel foil yang digunakan tebalnya kurang dari 25 mikron (Suyitno, 2007).

Alum adalah kelompok garam rangkap berhidrat berupa kristal dan bersifat isomorf dengan rumus molekul AlK $\left(\mathrm{SO}_{4}\right)_{2} \cdot 12 \mathrm{H}_{2} \mathrm{O}$. Alum merupakan senyawa yang tidak berwarna dan mempunyai bentuk kristal kubus ketika kalium sulfat dan aluminium sulfat keduanya dilarutkan dan didinginkan. Larutan alum kalium tersebut bersifat asam. Alum ini dikenal banyak sebagai koagulan dalam pengolahan air maupun limbah.

Aluminium sulfat merupakan salah satu komponen pembentuk senyawa alum. Aluminium sulfat berbentuk butiran halus berwarna putih keabu-abuan sampai coklat muda yang merupakan material asam dan bersifat korosif. Bentuk yang biasa digunakan sebagai koagulan adalah $\mathrm{Al}_{2}(\mathrm{SO} 4)_{3} .14 \quad \mathrm{H}_{2} \mathrm{O}$. Aluminium sulfat bereaksi di dalam air dalam suasana alkali membentuk endapan aluminium hidroksida. Aluminium sulfat membentuk garamgaram rangkap dengan sulfat dari kation-kation monovalen dengan bentuk-bentuk kristal yang menarik yang disebut alum atau tawas. Garam rangkap hanya dapat bertahan pada bentuk padat. Ketika alum dilarutkan dalam air larutan akan mengandung ion $\mathrm{K}^{+}, \mathrm{Al}^{3+}$ dan $\mathrm{SO}_{4}{ }^{2-}$ (Vogel, 1985). 


\section{METODOLOGI PENELITIAN}

\section{Bahan Penelitian}

Bahan baku yang digunakan pada penelitian ini adalah aluminium foil yang berasal dari limbah blister obat.

Bahan yang digunakan untuk proses pembuatan senyawa alum dan analisa kualitasnya antara lain $\mathrm{KOH}$ padatan, $\mathrm{H}_{2} \mathrm{SO}_{4} 6 \mathrm{M}$, Air suling, $\mathrm{BaCl}_{2} 10 \%$, $\mathrm{NH}_{4} \mathrm{OH}$ pekat, EDTA padatan, Dithizon serbuk, $\mathrm{ZnCl}_{2}$ padatan, Ammonium Asetat padatan, Asam Asetat Glasial.

\section{Alat Penelitian}

Heater dan mixer, Kondensor dan statif, Erlenmeyer asah $150 \mathrm{ml}$, Erlenmeyer $300 \mathrm{ml}$, Pipet tetes, Corong, Beaker glass $100 \mathrm{ml}, 200 \mathrm{ml}$ dan $500 \mathrm{ml}$, Kertas saring, Tabung reaksi, Buret, Spatula, Neraca analitik, Melting Point Butchi, Bunsen, Labu dasar bulat.

\section{Metode Penelitian}

Penelitian dilakukan dengan variabel lamanya waktu pada saat pemanasan aluminium foil yang terdapat pada blister, dimana konsentrasi $\mathrm{KOH}$ dan berat aluminium foil yang digunakan tetap.

\section{Analisa kadar aluminium dalam foil} Menimbang1 gram aluminium foil dalam gelas kimia $100 \mathrm{ml}$. Merendam aluminium foil tersebut dalam larutan $\mathrm{NaOH} 30 \%$ pada suhu $70^{\circ} \mathrm{C}-80^{\circ} \mathrm{C}$ hingga tersisa lapisan bening PVC. Mengeringkan lapisan PVC dalam oven pada suhu $50^{\circ} \mathrm{C}$ kemudian timbang. Menghitung selisih berat aluminium foil dengan berat PVC hasil perendaman. Berat aluminium adalah berat yang hilang selama proses perendaman. Menghitung kadar aluminium dalam foil.

Pembuatan senyawa alum dari aluminium foil limbah blister obat dengan variabel waktu pemanasan 1 jam, 2 jam, 3 jam, 4 jam, 5 jam dan 6 jam dengan konsentrasi KOH $15 \%$.

Menyiapkan bahan baku blister obat kemudian pisahkan lapisan aluminium foil dari blister obat tersebut. Aluminium foil yang telah dipisahkan kemudian dibersihkan dan digunting hingga berukuran kurang lebih $1 \mathrm{~cm}^{2}$. Potongan aluminium foil kemudian ditimbang sebanyak 1 gram kedalam erlenmeyer asah $150 \mathrm{ml}$. Tambahkan

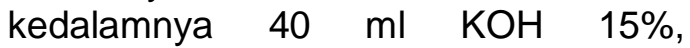
kemudian dipanaskan di atas hotplate dengan kondensor selama 1 jam pada suhu $80^{\circ} \mathrm{C}$. Larutan hasil pemanasan disaring, kemudian ditambahkan kedalamnya secara perlahan menggunakan pipet tetes $25 \mathrm{ml} \mathrm{H}_{2} \mathrm{SO}_{4}$ $6 \mathrm{M}$ sambil diaduk. Larutan kemudian dipanaskan pada suhu $70^{\circ} \mathrm{C}$ hingga jernih dan berkurang sepertiga volumenya. Larutan yang sudah jernih kemudian didinginkan dan didiamkan pada suhu kamar selama 3 hari hingga terbentuk kristal alum. Kristal alum yang terbentuk disaring dengan menggunakan kertas saring whatman 41 yang telah diketahui beratnya, kemudian dicuci dengan $20 \mathrm{ml}$ etanol $95 \%$. Kristal alum beserta kertas saring dikeringkan di udara terbuka kemudian ditimbang dan dihitung berat kristal alum yang didapat. Langkah 3 hingga 9 dilakukan kembali dengan variasi waktu pemanasan yaitu 2 jam, 3 jam, 4 jam, 5 jam dan 6 jam.

Uji Kualitas Alum (AIK $\left(\mathrm{SO}_{4}\right)_{2} \cdot \mathbf{1 2}_{2} \mathrm{O}$ ) Parameter serta spesifikasi pengujian dilakukan berdasarkan pada United State Pharmacopeia Edisi 30.

Parameter pengujian meliputi :

Tabel 1. Parameter uji dan spesifikasi alum

\begin{tabular}{|c|l|l|}
\hline No. & \multicolumn{1}{|c|}{ Parameter Uji } & \multicolumn{1}{|c|}{ Spesifikasi } \\
\hline 1 & Fisik & $\begin{array}{l}\text { Padatan berupa } \\
\text { kristal tidak berwarna } \\
\text { hingga putih }\end{array}$ \\
\hline 2 & Kelarutan & $\begin{array}{l}\text { Larut dalam air dan } \\
\text { tidak larut dalam } \\
\text { etanol 95\% }\end{array}$ \\
\hline 3 & pH larutan & $\begin{array}{l}3.0-3.5 \quad \text { (larutan } \\
10 \%\end{array}$ \\
\hline 4 & Titik leleh & $92.5{ }^{\circ} \mathrm{C}$ \\
\hline 5 & Uji Potassium & Positif \\
\hline
\end{tabular}




\begin{tabular}{|c|l|lr|}
6 & Uji Aluminium & Positif & \\
\hline 7 & Uji Sulfat & Positif & \\
\hline 8 & $\begin{array}{l}\text { Kemurnian alum, } \\
\text { AlK }\left(\mathrm{SO}_{4}\right)_{2} .12 . \mathrm{H}_{2} \mathrm{O}\end{array}$ & $\begin{array}{l}\text { Tidak } \\
99.0 \%\end{array}$ \\
\hline
\end{tabular}

\section{Uji Fisik}

Mengambil sedikit sampel, letakkan diatas kaca arloji dengan alas berwarna hitam. Mengamati warna serta bentuk dari sampel lalu dibandingkan terhadap spesifikasi.

\section{Uji Kelarutan}

Menimbang 1 gram sampel kemudian larutkan dalam $10 \mathrm{~mL}$ air suling. Mengamati larutan, sampel harus larut seluruhnya dalam air. Mengambil sedikit sampel masukkan kedalam tabung reaksi yang berisi etanol 95\%. Mengamati larutan, sampel tidak larut dalam etanol $95 \%$.

\section{Mengukur pH Larutan}

Mengukur $\mathrm{pH}$ larutan yang telah dibuat pada uji kelarutan dengan menggunakan $\mathrm{pH}$ meter. $\mathrm{pH}$ larutan antara $3.0-3.5$.

\section{Mengukur Titik leleh}

Memasukkan sedikit sampel ke dalam pipa kapiler. Meletakkan pipa kapiler ke dalam slot pada alat Melting Point Butchi . Menaikkan suhu melting point secara perlahan sambil diamati kondisi sampel yang berada dalam pipa kapiler. Mencatat temperatur ketika sampel mulai meleleh.

\section{Uji Potasium}

Menyelupkan kawat Ni-Chrome ke dalam larutan $\mathrm{HCl}$ pekat. Mengambil sedikit kristal alum dengan menggunakan kawat Ni-Chrome tadi. Memanaskan bagian kawat Ni-Chrome yang terdapat kristal alum dengan menggunakan api oksidator bunsen (api biru). Adanya potasium ditunjukkan dengan nyala api berwarna merah lembayung.

\section{Uji Aluminium}

Melarutkan sedikit sampel kedalam tabung reaksi yang berisi air. Meneteskan kedalamnya larutan ammonium hidroksida pekat. Hasil positif ditunjukkan dengan terbentuknya endapan gelatin putih $\mathrm{Al}(\mathrm{OH})_{3}$. Endapan akan kembali larut ketika ditambahkan ammonium hidroksida berlebih.

\section{Uji Sulfat}

Melarutkan sedikit sampel ke dalam tabung reaksi yang berisi air. Meneteskan kedalamnya larutan $\mathrm{BaCl}_{2}$ $10 \%$. Hasil positif ditunjukkan dengan terbentuknya endapan putih $\mathrm{Ba}(\mathrm{SO})_{4}$.

\section{Kemurnian senyawa alum $\left(\mathrm{AlK}\left(\mathrm{SO}_{4}\right)_{2} .12 . \mathrm{H}_{2} \mathrm{O}\right)$}

Menimbang dengan tepat 2 gram sampel, larutkan dalam $25 \mathrm{ml}$ air suling. menambahkan kedalamnya 50,0 ml EDTA $0.1 \mathrm{M}$ dan didihkan selama 5 menit, dinginkan. Menambahkan $20 \mathrm{ml}$ larutan dapar Ammonium Asetat $\mathrm{pH}$ 4.5, $85 \mathrm{ml}$ etanol dan $2 \mathrm{ml}$ indikator dithizone. Menitrasi kelebihan EDTA dengan menggunakan larutan $\mathrm{ZnCl}_{2}$ 0,1 $M$ hingga warna berubah menjadi merah muda cerah. $1 \mathrm{ml}$ EDTA 0,1 M setara dengan 0,04744 gram AlK $\left(\mathrm{SO}_{4}\right)_{2} \cdot 12 \mathrm{H}_{2} \mathrm{O}$

\section{Metode Analisa Data}

Perhitungan Rendemen

$\% \quad$ Rendemen
$\frac{\text { Massa alum hasilpenelitian }}{\text { Massa bahan baku }} \times 100 \%$

Perhitungan Korelasi

$r^{2}=\frac{n \cdot \sum X Y-\sum X \cdot \Sigma Y}{\sqrt{\left(n \cdot \Sigma X^{2}\right)-\sum(X)^{2}}-\sqrt{\left(n \cdot \Sigma Y^{2}\right)-\sum(Y)^{2}}}$

Dimana :

$r=$ Nilai korelasi $(-1<r<1)$

$X=$ Variable yang ditentukan (waktu pemanasan)

$\mathrm{Y}=$ Variable yang terpengaruh (konversi reaksi dan rendemen alum)

$\mathrm{N}=$ Jumlah percobaan 


\section{Perhitungan Statistik}

Analisa statistik menggunakan metode "Least Square", dengan persamaan : $y=c x^{2}+b x+a$

Dimana harga a, b, c dihitung dengan menggunakan persamaan sebagai berikut ( $n=$ jumlah sampel) :

an $+b \sum x+c \sum x^{2}=\sum y$
$a \sum x+b \sum x^{2}+c \sum x^{3}=\sum x y$
$a \sum x^{2}+b \sum x^{3}+c \sum x^{4}=\sum x^{2} y$

\section{HASIL DAN PEMBAHASAN}

\section{Kadar aluminium dalam limbah foil blister}

Analisa kadar aluminium dalam limbah foil blister dengan metoda gravimetri dan didapatkan berat aluminium dalam 1 gram foil adalah 0,883 gram atau $88,3 \%$. Setelahnya dilakukan perhitungan berat teoritis alum secara stoikiometri dan diperoleh berat teoritis alum adalah 15,512 gram.

\section{Hasil rendemen.}

Berat senyawa alum yang diperoleh pada berbagai waktu pemanasan dan hasil perhitungan rendemen dapat dilihat pada tabel 2 .

Tabel 2. Berat dan rendemen alum pada berbagai waktu pemanasan.

\begin{tabular}{|c|c|c|c|}
\hline No. & $\begin{array}{c}\text { Waktu } \\
\text { Pemanasan } \\
\text { (Jam) }\end{array}$ & $\begin{array}{c}\text { Berat } \\
\text { Alum } \\
\text { (gram) }\end{array}$ & $\begin{array}{c}\text { Rendemen } \\
(\%)\end{array}$ \\
\hline 1. & 1 & 12,236 & 14,85 \\
\hline 2. & 2 & 12,878 & 15,62 \\
\hline 3. & 3 & 13,552 & 16,44 \\
\hline 4. & 4 & 13,299 & 16,14 \\
\hline 5. & 5 & 13,436 & 16,30 \\
\hline 6 & 6 & 13,202 & 16,02 \\
\hline
\end{tabular}

\section{Hasil Analisa Kualitas Alum}

Secara fisik semua kristal alum yang terbentuk pada berbagai waktu pemanasan memenuhi spesifikasi. Hasil analisa kualitas alum secara lengkap dapat di lihat pada tabel 2 dan tabel 3.

Tabel 3. Hasil analisa kualitas alum

\begin{tabular}{|c|c|c|c|c|c|}
\hline $\begin{array}{c}\text { Waktu } \\
\text { pemanasan } \\
\text { (jam) }\end{array}$ & $\mathrm{pH}$ & $\begin{array}{c}\text { Titik } \\
\text { leleh }\end{array}$ & $\begin{array}{c}\text { Uji } \\
\text { Kalium }\end{array}$ & $\begin{array}{c}\text { Uji } \\
\text { Aluminium }\end{array}$ & $\begin{array}{c}\text { Uji } \\
\text { Sulfat }\end{array}$ \\
\hline 1 & 3,05 & $92,2^{\circ} \mathrm{C}$ & $(+)$ & $(+)$ & $(+)$ \\
\hline 2 & 3,22 & $92,5^{\circ} \mathrm{C}$ & $(+)$ & $(+)$ & $(+)$ \\
\hline 3 & 3,10 & $92,8^{\circ} \mathrm{C}$ & $(+)$ & $(+)$ & $(+)$ \\
\hline 4 & 3,15 & $92,0^{\circ} \mathrm{C}$ & $(+)$ & $(+)$ & $(+)$ \\
\hline 5 & 3,13 & $92,2^{\circ} \mathrm{C}$ & $(+)$ & $(+)$ & $(+)$ \\
\hline 6 & 3,10 & $91,7^{\circ} \mathrm{C}$ & $(+)$ & $(+)$ & $(+)$ \\
\hline
\end{tabular}

Tabel 4.Hubungan antara waktu pemanasan dengan kemurnian alum

\begin{tabular}{|c|c|c|}
\hline $\begin{array}{l}\text { Waktu } \\
\text { Pemanasan } \\
\text { (Jam) }\end{array}$ & $\begin{array}{c}\text { Kemurnian } \\
(\%)\end{array}$ & $\begin{array}{c}\text { Kemurnian rata-rata } \\
(\%)\end{array}$ \\
\hline \multirow{2}{*}{1} & 99,62 & 99,51 \\
\cline { 2 - 2 } 2 & 99,39 & \multirow{2}{*}{9} \\
\hline \multirow{2}{*}{2} & 98,68 & 98,62 \\
\cline { 2 - 2 } & 98,56 & \\
\hline \multirow{2}{*}{3} & 99,15 & 99,27 \\
\cline { 2 - 2 } & 99,39 & 9 \\
\hline \multirow{2}{*}{4} & 99,15 & 99,39 \\
\cline { 2 - 2 } & 99,62 & \\
\hline
\end{tabular}




\begin{tabular}{|l|l|l|}
\multirow{2}{*}{5} & 98,32 & \multirow{2}{*}{98,26} \\
\cline { 2 - 2 } & 98,20 & \\
\hline \multirow{2}{*}{6} & 98,68 & \multirow{2}{*}{98,62} \\
\cline { 2 - 2 } & 98,56 & \\
\hline
\end{tabular}

\section{Pembahasan}

Produk yang dihasilkan dari penelitian ini yaitu senyawa alum AlK $\left(\mathrm{SO}_{4}\right)_{2} \cdot 12 \cdot \mathrm{H}_{2} \mathrm{O}$. Proses awal dari pembuatan senyawa alum ini adalah dengan memisahkan aluminium foil yang melekat pada PVC, karena foil inilah yang kemudian akan dijadikan bahan baku utama dalam pembuatan alum. Aluminium foil yang sudah dipisahkan dari PVC lalu dipotong hingga berukuran kurang lebih $1 \mathrm{~cm}^{2}$, hal ini bertujuan agar reaksi yang terjadi antara aluminium foil dan $\mathrm{KOH}$ berlangsung lebih cepat karena salah satu faktor yang dapat memepengaruhi laju reaksi adalah frekuensi tumbukan. Semakin banyak tumbukan maka semakin cepat pula reaksi itu berlangsung. Selain itu untuk mempercepat proses reaksi maka dilakukan juga proses pengadukan dan pemanasan pada suhu $80^{\circ} \mathrm{C}$, proses pemanasan tidak boleh dilakukan pada suhu yang terlalu tinggi mengingat reaksi ini bersifat eksotermis dan akan menyebabkan letupan-letupan.

Reaksi alumunium dengan $\mathrm{KOH}$ akan menghasilkan gas $\mathrm{H}_{2}$ sesuai reaksi :

$2 \mathrm{Al}+2 \mathrm{KOH}+6 \mathrm{H}_{2} \mathrm{O} \longrightarrow 2 \mathrm{KAI}(\mathrm{OH})_{4}+$ $3 \mathrm{H}_{2}$

Setelah dipanaskan, larutan disaring untuk menghilangkan residu dan filtratnya ditampung dengan menggunakan gelas kimia. Selanjutnya filtrat dipanaskan pada suhu $70^{\circ} \mathrm{C}$ dan ditambahkan kedalamnya larutan $\mathrm{H}_{2} \mathrm{SO}_{4} 6 \mathrm{M}$ sebanyak $25 \mathrm{ml}$ secara perlahan karena reaksi bersifat eksotermis. Reaksi yang terjadi adalah

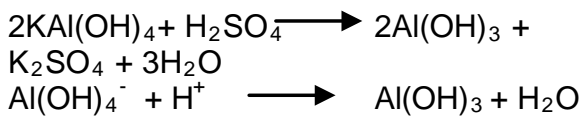

Tujuan penambahan larutan $\mathrm{H}_{2} \mathrm{SO}_{4} 6 \mathrm{M}$ berlebih dilakukan agar seluruh senyawa $\mathrm{KAI}(\mathrm{OH})_{4}$ dapat bereaksi sempurna. $\mathrm{Al}(\mathrm{OH})_{3}$ yang terbentuk langsung bereaksi dengan $\mathrm{H}_{2} \mathrm{SO}_{4}$ dengan persamaan reaksi sebagai berikut :

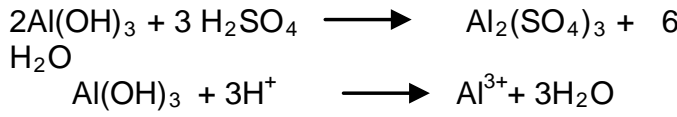

Setelah larutan $\mathrm{H}_{2} \mathrm{SO}_{4} 6 \mathrm{M}$ ditambahkan seluruhnya, larutan kemudian didinginkan pada suhu kamar selama 3 hari hingga terbentuk kristal alum. Kristal alum yang terbentuk lalu disaring dan dicuci dengan menggunakan etanol, hal ini bertujuan untuk mencuci residu $\mathrm{H}_{2} \mathrm{SO}_{4}$ dan mempercepat pengeringan.

Hubungan antara variable waktu pemanasan aluminium foil dengan rendemen alum yang diperoleh dapat dilihat pada gambar 1 berikut:

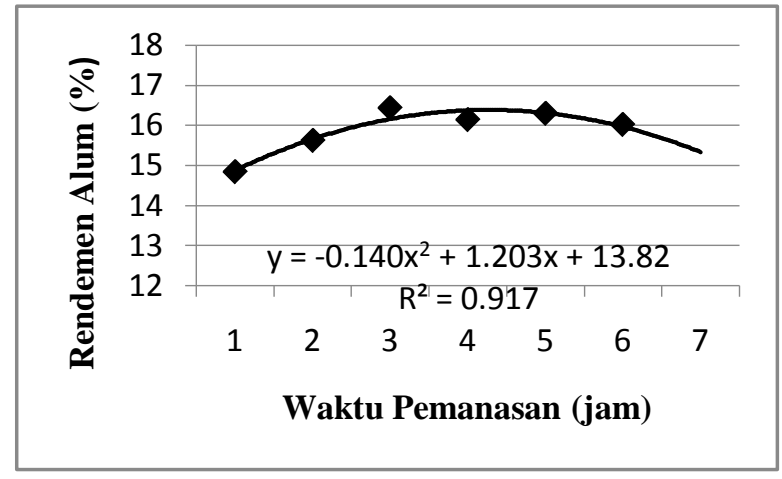

Gambar 1. Hubungan waktu pemanasan (jam) dengan rendemen (\%).

Gambar 1 menunjukkan hubungan antara waktu pemanasan dengan rendemen alum yang diperoleh. Dari gambar tersebut dapat dilihat bahwa dengan semakin lamanya proses pemanasan maka rendemen yang dihasilkan semakin tinggi. Hal ini terjadi karena dengan semakin lama waktu pemanasan maka kesempatan antara aluminium untuk bereaksi seluruhnya dengan $\mathrm{KOH}$ semakin besar sehingga diperoleh rendemen yang besar pula. 
Waktu optimum pemanasan yang diperoleh adalah pada waktu pemanasan 3 jam dengan rendemen $16,44 \%$. Setelah melewati titik optimum rendemen alum yang diperoleh tidak berubah secara signifikan.

Hubungan antara waktu pemanasan dengan rendemen alum yang diperoleh dapat ditulis dengan persamaan polinomial:

$$
y=-0,140 x^{2}+1,203 x+13,82
$$

dimana $x$ adalah waktu pemanasan (jam) dan y adalah rendemen alum (\%).

Dari hasil analisa kualitas alum, didapatkan semua alum yang diperoleh pada berbagai waktu pemanasan telah memenuhi spesifikasi uji fisik dan identifikasi unsur. Dari segi kemurnian, alum yang diperoleh berada pada kisaran 98,26\% - 99,51\% dimana kadar tertinggi diperoleh pada waktu pemanasan 1 jam yaitu sebesar 99,51\%. Hubungan antara waktu pemanasan dengan kemurnian alum yang diperoleh dapat dilihat pada gambar 2.

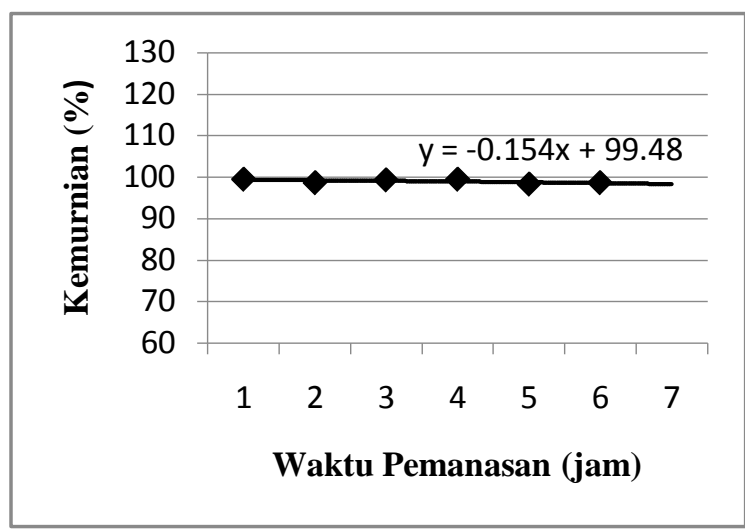

Gambar 2. Hubungan waktu pemanasan (jam) dengan kemurnian alum (\%).

Dari tabel 2 dan 3 didapatkan tidak adanya korelasi yang mencolok antara lamanya waktu pemasanan terhadap kualitas alum yang diperoleh, baik dari sifat fisik mau pun kemurniannya. Lama waktu pemanasan hanya mempengaruhi rendemen alum saja.

\section{KESIMPULAN DAN SARAN}

\section{Kesimpulan}

Dari penelitian yang telah dilakukan berdasarkan pada variable lamanya waktu pemanasan 1 jam, 2 jam, 3 jam, 4 jam, 5 jam dan 6 jam dengan konsentrasi $\mathrm{KOH} 15 \%$ dan konsentrasi $\mathrm{H}_{2} \mathrm{SO}_{4} 6 \mathrm{M}$ diperoleh hasil rendemen tertinggi pada waktu pemanasan 3 jam dengan rendemen $16,44 \%$, sedangkan kemurnian senyawa alum tertinggi diperoleh pada waktu pemanasan 1 jam dengan kemurnian 99,51 \%. Dari data tersebut, disimpulkan bahwa senyawa alum yang diperoleh dari bahan baku aluminium foil limbah blister dapat dimanfaatkan untuk kebutuhan industri farmasi.

Hubungan antara waktu pemanasan dengan rendemen alum yang diperoleh dapat ditulis dengan persamaan polinomial:

$$
y=-0,140 x^{2}+1,203 x+13,82
$$

dimana $x$ adalah waktu pemanasan (jam) dan y adalah rendemen (\%).

\section{Saran}

Ditinjau dari hasil penelitian dan kesimpulan yang diperoleh maka ada beberapa saran yang dapat menjadi masukkan bagi para pembaca dan para pelajar khususnya bagi yang ingin meneliti pada bidang serupa yaitu:

1. Perlu diperhatikan mengenai kebersihan bahan baku yang dipakai agar diperoleh kemurnian alum yang lebih tinggi lagi.

2. Untuk penelitian lebih lanjut, dapat dilakukan dengan variable waktu pemanasan yang lebih sempit, agar diperoleh waktu optimal pemanasan yang lebih akurat.

3. Lakukan analisa kualitas alum yang lebih lengkap agar alum yang diperoleh dapat lebih terjamin kualitasnya sehingga memenuhi spesifikasi sebagai bahan baku di industri farmasi. 


\section{DAFTAR PUSTAKA}

The United StatePhamacopeia (USP) $30 t^{h}$ Edition. United State:The United States Pharmacopeia Convention.

Astawan, M, 2008. Keunggulan Aluminium Foil \& Logam.

Bloch, M. 2013. How long does $X$ take to break down?. Green living Tip

Martindale. 1993. The Extra Pharmacopeiac Thirtieth Edition. London: The Pharmaceutical Press.

Pilchik, R., 2000. Pharmaceutical Blister Packaging, Part I Rationale and Materials.

www.pharmanet.com.br/pdf/blister.pdf

Suyitno. 1990. Bahan-bahan Pengemas. Yogyakarta: UGM.

Vogel. 1985. Buku Teks Analisis Anorganik Kualitatif Makro dan Semimikro. Edisi ke lima Bagian 1. Jakarta: PT. Kalman Media Pusaka. 